\title{
Administration of amino acid agents is effective to prevent critical alkalosis during sodium bicarbonate irrigation in patients with pseudomyxoma peritonei
}

\author{
Soshi Kusunoki $\cdot$ Hiroshi Kaneda $\cdot$ Shin Suga $\cdot$ \\ Miki Kimura • Yasuhisa Terao $\cdot$ Kiyoko Kato · \\ Takashi Yao $\cdot$ Satoru Takeda
}

Received: 24 August 2011/Accepted: 22 December 2011/Published online: 9 February 2012

(C) The Japan Society of Clinical Oncology 2012

\begin{abstract}
Pseudomyxoma peritonei (PMP) is a rare disease, which presents with large amounts of mucinous ascites. The primary tumor is usually a mucinous cystadenoma or cystadenocarcinoma of the appendix. The main treatment is surgical resection of the tumor and removal of the mucus, but it can be challenging to remove mucus completely. Intraperitoneal irrigation with $7 \%$ sodium bicarbonate was effective as a mucolytic agent. However, it has been reported that alkalosis can occur during irrigation. Currently there is a paucity of evidence regarding the mechanisms that lead to alkalosis. We report our experience with two cases of PMP who underwent intraperitoneal irrigation with $7 \%$ sodium bicarbonate. In one case, critical alkalosis ( $\mathrm{pH} 7.56, \mathrm{HCO}_{3}{ }^{-} 35.2 \mathrm{mmol} / \mathrm{ml}$ ) occurred after irrigation with $7 \%$ sodium bicarbonate and gradually improved over time. Blood gas abnormalities resolved during the postoperative period. A salpingo-oophorectomy, omentectomy, and appendectomy were performed. Review of the histology confirmed a mucinous tumor of low malignant potential of the appendix. In the second described case, we administered amino acid agents intravenously followed by intraperitoneal irrigation with $7 \%$ sodium bicarbonate. Critical alkalosis did not occur. A total abdominal hysterectomy, bilateral salpingo-oophorectomy,
\end{abstract}

\footnotetext{
S. Kusunoki $\cdot$ H. Kaneda $\cdot$ S. Suga $\cdot$ M. Kimura $\cdot$ Y. Terao $\cdot$

K. Kato $(\bowtie) \cdot$ S. Takeda

Department of Obstetrics and Gynecology, Faculty of Medicine, Juntendo University, Hongo2-1-1, Bunkyo-ku,

Tokyo 113-8431, Japan

e-mail:kkato@juntendo.ac.jp

T. Yao

Department of Human Pathology, Faculty of Medicine,

Juntendo University, Hongo2-1-1, Bunkyo-ku,

Tokyo 113-8431, Japan
}

and appendectomy were performed. Review of the histology confirmed an appendiceal mucinous cystadenocarcinoma with metastases in bilateral ovaries. Mucus in the peritoneal cavity was almost completely removed in both these cases. Both patients are doing well with no evidence of recurrence. Administration of amino acid agents followed by intraperitoneal irrigation with $7 \%$ sodium bicarbonate appears to be an effective therapy to prevent critical alkalosis in patients with PMP.

Keywords Pseudomyxoma peritonei . Sodium bicarbonate $\cdot$ Alkalosis

\section{Introduction}

Pseudomyxoma peritonei (PMP) is a rare disease involving mucinous tumors of the appendix and ovaries in the peritoneal cavity. The frequency lies in the region of 1 in 1,000,000 individuals, mainly affecting women aged between 40 and 50 years. The primary tumor is often a mucinous cystadenoma or cystadenocarcinoma of the appendix. In most cases of mucinous ovarian tumor, involvement is via a metastasis from the appendix or other gastrointestinal source. The term PMP has been applied historically as a pathologic diagnostic term for both benign and malignant mucinous neoplasms that produce mucin in the peritoneal cavity. Recently, a pathologic classification has been described that separates patients into prognostic categories and is divided into two types: disseminated peritoneal adenomucinosis (DPAM), and peritoneal mucinous carcinomatosis (PMCA) $[1,2]$. The main treatment is surgical resection of the tumor and removal of mucus, but it is often challenging to remove the mucus completely. Debulking surgery often includes removal of omentum, colon, uterus, ovary, bladder, liver, pancreas, 
spleen, and stomach, as well as peritonectomy. PMP exhibits a malignant clinical course, including accumulation of mucus and intestinal obstruction by tumor masses. Recent evidence suggests that intraperitoneal irrigation with sodium bicarbonate is effective [3-5]. However, it has been reported that critical alkalosis may occur during therapy. We report our experience with two cases of PMP treated with intraperitoneal irrigation with $7 \%$ sodium bicarbonate (Table 1). In one of these cases, we administered amino acid agents before irrigation. This appeared effective in preventing critical alkalosis during irrigation.

We now present two cases: the first a case of alkalosis after irrigation with $7 \%$ sodium bicarbonate without prior administration of amino acid agents and conversely a case of successful prevention of critical alkalosis with preadministration of amino acid agents.

\section{Case report}

Case 1

A 42-year-old woman was admitted to hospital with complaints of abdominal distension for the last 6 months and was referred to our hospital. Vaginal ultrasonography showed an echogenic, cystic mass with solid components, $60 \mathrm{~mm}$ in size. Laboratory examination showed an increase in serum levels of tumor markers (CEA $20.2 \mathrm{ng} / \mathrm{ml}, \mathrm{CA} 72$ $4=79.3 \mathrm{U} / \mathrm{ml}, \mathrm{CA} 125=73 \mathrm{U} / \mathrm{ml})$. Cytological analysis of ascites and histopathological analysis of the endocervix and endometrium were normal. Ascitic fluid was consistent with mucinous liquid. Pelvic magnetic resonance imaging (MRI) revealed a large volume of ascites and a right cystic ovarian tumor, $10 \mathrm{~mm}$ in diameter with a cyst, containing fat.

Exploratory laparotomy revealed a large volume of mucinous ascites $(5000 \mathrm{ml})$, and a right ovary $60 \mathrm{~mm}$ in diameter, containing fat. Mucus was removed by intraperitoneal irrigation with $7 \%$ sodium bicarbonate. Right salpingo-oophorectomy, appendectomy, omentectomy, and tumorectomy were performed. During the operation, blood gas analysis (BGA) demonstrated a rise in $\mathrm{HCO}_{3}{ }^{-}$to $35.2 \mathrm{mmol} / \mathrm{l}$ and a rise in $\mathrm{pH}$ to 7.56 , after $5 \mathrm{~min}$ of irrigation with sodium bicarbonate. $\mathrm{HCO}_{3}{ }^{-}$and $\mathrm{pH}$ decreased gradually and levels normalized upon return to the ward. The electrolytes on BGA were within normal limits (Fig. 1). Histopathological examination of the appendix revealed a mucinous tumor of low malignant potential and examination of the right ovary revealed a mature cystic teratoma (Fig. 2).

Table 1 Summary of clinicopathologic findings and follow-up data for two cases of PMP

\begin{tabular}{|c|c|c|c|c|c|c|c|c|c|}
\hline Patient & $\begin{array}{l}\text { Age } \\
\text { (years) }\end{array}$ & Presentation & Surgery & $\begin{array}{l}\text { Appendix } \\
\text { pathology }\end{array}$ & $\begin{array}{l}\text { Adjuvant } \\
\text { therapy }\end{array}$ & Follow-up & Irrigation & $\begin{array}{l}\text { Administration } \\
\text { of amino acid }\end{array}$ & $\begin{array}{l}\text { Critical } \\
\text { alkalosis } \\
(\mathrm{pH}>7.55)\end{array}$ \\
\hline 1 & 42 & Pelvic mass & $\begin{array}{l}\text { BSO } \\
\text { appendectomy }\end{array}$ & LMP & None & $\begin{array}{l}\text { ANED } \\
\text { (50 months) }\end{array}$ & Done & No & Yes \\
\hline 2 & 78 & Pelvic mass & $\begin{array}{l}\text { TAH, BSO } \\
\text { appendectomy }\end{array}$ & Adenocarcinoma & None & $\begin{array}{l}\text { ANED } \\
\text { (16 months) }\end{array}$ & Done & Done & No \\
\hline
\end{tabular}

We suggest that severe alkalosis during irrigation with $7 \%$ sodium bicarbonate can be prevented using our treatment protocol $A N E D$ alive no evidence of disease, BSO bilateral salpingo-oophorectomy, LMP low malignant potential, TAH total abdominal hysterectomy

Fig. 1 BGA showed $\mathrm{HCO}_{3}{ }^{-}$ increased to $35.2 \mathrm{mmol} / \mathrm{l}$ and $\mathrm{pH}$ increased to 7.56 within 5 min after using sodium bicarbonate. $\mathrm{HCO}_{3}{ }^{-}$and $\mathrm{pH}$ decreased gradually and normalized upon return to the ward. The electrolytes on BGA were within normal limits
Passage during operation (case 1)

\begin{tabular}{ccccccc}
\hline & ope start & irrigation $5 \mathrm{~min}$ & $10 \mathrm{~min}$ & $20 \mathrm{~min}$ & $60 \mathrm{~min}$ & $100 \mathrm{~min}$ \\
\hline $\mathrm{pH}$ & $\mathbf{7 . 4 7}$ & $\mathbf{7 . 5 6}$ & $\mathbf{7 . 5 6}$ & $\mathbf{7 . 4 9}$ & $\mathbf{7 . 4 5}$ & $\mathbf{7 . 4 5}$ \\
$\mathrm{PaCO}_{2}$ & 35.3 & 26.3 & 29.2 & 36.2 & 36.7 & 33.4 \\
$\mathrm{HCO}_{3}{ }^{-}$ & 23.3 & 35.2 & 30.2 & $\mathbf{2 5 . 6}$ & $\mathbf{2 4 . 9}$ & 23 \\
$\mathrm{BE}$ & 1.7 & 1.9 & 2.6 & 2 & $\mathbf{1}$ & -0.4 \\
$\mathrm{Na}^{+}$ & 139 & 134 & 133 & 129 & 133 & 142 \\
$\mathrm{~K}^{+}$ & 3.61 & 3.9 & 3.88 & 4.01 & 3.5 & 2.84 \\
$\mathrm{Ca}^{2+}$ & 1.15 & 1.09 & 1.06 & 1.08 & 1.08 & 1 \\
$\mathrm{Cl}^{-}$ & 106 & 106 & 106 & 102 & 105 & 113 \\
\hline
\end{tabular}


The postoperative course was uneventful and follow-up investigations 50 months later demonstrated that the patient was disease- and symptom-free with no complications related to any therapeutic regimen.

\section{Case 2}

A 78-year-old woman was referred to our hospital because of lower abdominal pain. Vaginal ultrasonography showed a large amount of ascites and multicystic masses occupying the peritoneal cavity. Laboratory examination demonstrated an increase in serum levels of tumor markers (CEA $22.4 \mathrm{ng} / \mathrm{ml}, \quad$ CA19-9 = $93 \mathrm{U} / \mathrm{ml}, \quad$ CA125 = $50 \mathrm{U} / \mathrm{ml})$.

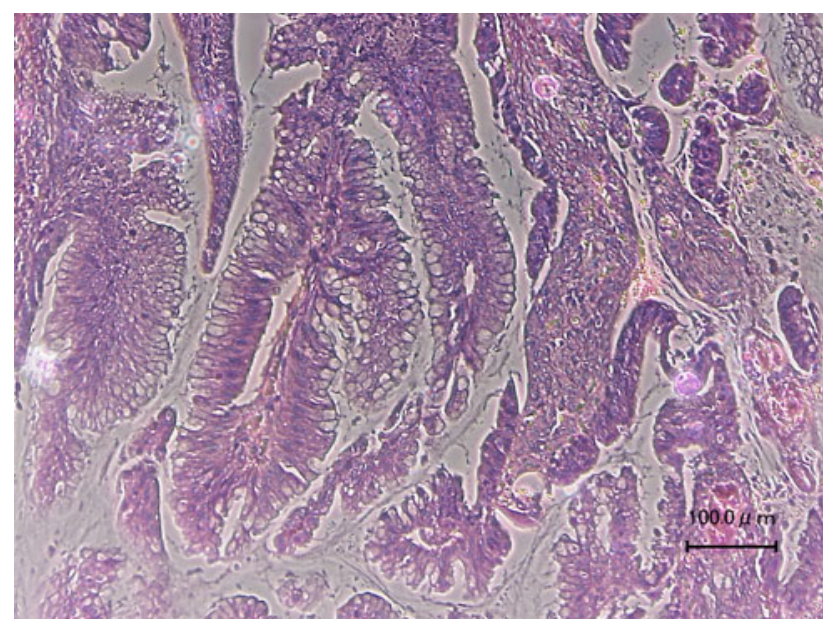

Fig. 2 Microscopic sections showing a mucinous tumor of low malignant potential
Cytological and histopathological analyses of ascites, endocervix, and endometrium were normal. Pelvic MRI revealed a large volume of ascites, thickened peritoneum, and a right ovarian tumor $10 \mathrm{~mm}$ in diameter. Ascites was mucinous in nature.

Exploratory laparotomy was performed and upon entry to the abdomen, the colon, uterus, and ovaries were adherent to each other and massive mucinous ascites (approximately $2000 \mathrm{ml}$ ) was discovered. From prior experience with PMP, in which alkalosis occurred during irrigation with sodium bicarbonate, we planned to administer amino acid agents before irrigation to prevent alkalosis. We administered amino acid agents (Aminoleban ${ }^{\circledR}$ $100 \mathrm{ml} / \mathrm{min}$ ) followed by intraperitoneal irrigation with $7 \%$ sodium bicarbonate. A mild elevation of $\mathrm{pH}$ and $\mathrm{HCO}_{3}{ }^{-}$ was experienced (Fig. 3). However, this was much less severe than the degree of alkalosis seen in case 1 . The patient underwent transabdominal hysterectomy, bilateral salpingo-oophorectomy, and appendectomy. Histopathological analysis of the appendix revealed adenocarcinoma with PMP (Fig. 4).

The patient was discharged 14 days after the operation. Follow-up investigations 16 months postoperatively reveal that the patient is disease- and symptom-free and has not developed any complications related to any therapeutic regimen.

\section{Discussion}

PMP is characterized by large amounts of mucinous ascites. Perforation of a mucinous tumor results in peritoneal

Passage during operation (case 2)

\begin{tabular}{ccccccccccc}
\hline & ope start & $1 \mathrm{~h}$ & $2 \mathrm{~h}$ & irrigation $5 \mathrm{~min}$ & $10 \mathrm{~min}$ & $15 \mathrm{~min}$ & $30 \mathrm{~min}$ & $45 \mathrm{~min}$ & $60 \mathrm{~min}$ & $90 \mathrm{~min}$ \\
\hline $\mathrm{pH}$ & 7.4 & 7.43 & 7.38 & 7.478 & 7.463 & 7.46 & $\mathbf{7 . 5 3}$ & $\mathbf{7 . 5 1}$ & $\mathbf{7 . 5}$ & 7.44 \\
$\mathrm{PaCO}_{2}$ & 29.3 & 39.7 & 40.8 & 33 & 37.4 & 42.4 & 39.9 & 40.8 & 37 & 34.4 \\
$\mathrm{HCO}_{3}^{-}$ & 27.4 & 25.7 & 23.6 & 23.9 & $\mathbf{2 6 . 2}$ & $\mathbf{2 9 . 8}$ & $\mathbf{3 2 . 7}$ & $\mathbf{3 4}$ & $\mathbf{3 0 . 4}$ & $\mathbf{2 6 . 2}$ \\
$\mathrm{BE}$ & 5.4 & 1.3 & -1.4 & 0.7 & 2.4 & $\mathbf{5 . 5}$ & $\mathbf{9 . 3}$ & $\mathbf{1 0 . 6}$ & $\mathbf{7 . 3}$ & $\mathbf{3 . 1}$ \\
$\mathrm{Na}^{+}$ & 129 & 127 & 127 & 127 & 126 & 126 & 128 & 128 & 133 & 133 \\
$\mathrm{~K}^{+}$ & 3 & 3.78 & 4.2 & 4.2 & 4.1 & 4.1 & 3.9 & 3.6 & 3.5 & 3.4 \\
$\mathrm{Ca}^{2+}$ & 1.06 & 1.05 & 1.09 & 1.08 & 1.05 & 1.03 & 0.97 & 1.02 & 0.98 & 1.04 \\
$\mathrm{Cl}^{-}$ & 103 & 103 & 104 & 104 & 102 & 99 & 99 & 99 & 102 & 105 \\
\hline
\end{tabular}

Fig. 3 By administering amino acid agents (Aminoleban ${ }^{\circledR} 100 \mathrm{ml} / \mathrm{h}$ ) followed by intraperitoneal irrigation with $7 \%$ sodium bicarbonate, severe alkalosis was mitigated against. A mild elevation of $\mathrm{pH}$ and $\mathrm{HCO}_{3}{ }^{-}$was still seen 


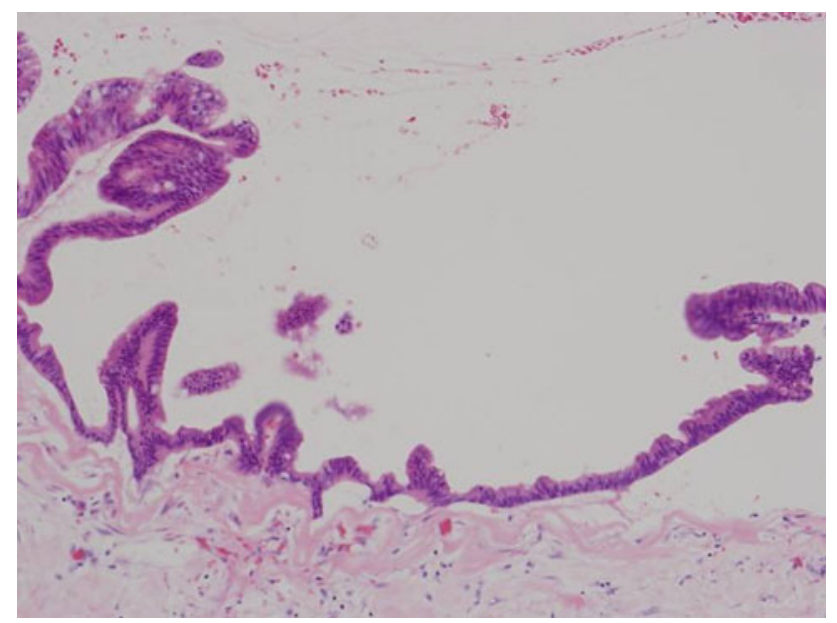

Fig. 4 Microscopic sections showing adenocarcinoma with PMP

dissemination of mucin. The tumor most commonly originates from the appendix or the ovary. Surgical resection of the tumor, removal of mucus, and appendectomy are initial therapeutic procedures. Several approaches using 5 or $10 \%$ dextrose and dextran sulfate have been reported for irrigation of the peritoneal cavity [6]. These therapies are not uniformly effective and hyperglycemia following intraperitoneal irrigation with $10 \%$ dextrose has been reported [7, 8]. 5-Fluorouracil, CDDP, doxorubicin, mitomycin $\mathrm{C}$ as postoperative systemic chemotherapy or HIPEC (hyperthermia and intraperitoneal chemotherapy) has also been reported as a treatment for PMP [2]. Several reports suggest that HIPEC minimizes treatment-related morbidity and mortality [9-11]; however, this procedure requires an institution that has specialized human resources and complex technological facilities, and requires particular vigilance for postoperative complications.

Watanabe et al. [3] described the efficacy of sodium bicarbonate with PMP in 1991. Mucin is a compound from a family of large, heavily glycosylated proteins and is soluble in alkali. Therefore, intraperitoneal irrigation with sodium bicarbonate has been useful with PMP, but the peritoneal capillary vessels absorb sodium bicarbonate in the abdominal cavity and this may lead to severe alkalosis.

Alkalosis is a condition diagnosed by BGA demonstrating alkalemia $\left(\mathrm{pH}>7.45, \mathrm{HCO}_{3}{ }^{-}>26 \mathrm{mEq} / \mathrm{l}, \mathrm{BE}\right.$ (base excess) $>+2 \mathrm{mEq} / \mathrm{l})$. It causes diffuse anterior cerebral blood flow constriction with reduction in tissue perfusion, and alkalosis may lead to tetany, seizures, and decreased mental status. Alkalosis also induces hypokalemia and hypocalcemia, which may lead to neuromuscular weakness and arrhythmias. Severe alkalosis may even lead to death. Critical alkalosis following irrigation with sodium bicarbonate has been reported previously [5]. The authors suggest that a $\mathrm{pH}$ and bicarbonate greater than 7.55 and $35 \mathrm{mEq} / \mathrm{l}$, respectively, should prompt appropriate therapy as necessary. In our first presented case, elevation of $\mathrm{pH}$ and $\mathrm{HCO}_{3}{ }^{-}$(pH 7.56, $\left.\mathrm{HCO}_{3}{ }^{-} 35.2 \mathrm{mEq} / \mathrm{l}\right)$ was recognized after $5 \mathrm{~min}$ of irrigation during the operation. As a means to reduce the alkalotic burden delivered to the patient, a reduction in the length of time for irrigation may be important, thus decreasing the total exposure of the patient to sodium bicarbonate. However, it is difficult to prevent alkalosis completely. Administration of amino acids prior to infusion of sodium bicarbonate was tried in case 2 to prevent such a severe alkalosis.

There are several amino acid agents using branchedchain amino acids for the treatment of liver failure or kidney failure, etc. Ammonia, produced by a dysfunction of amino acid metabolism, is toxic and must be removed from the body. The urea cycle describes the conversion reactions of ammonia into urea. Since these reactions occur in the liver, the urea is then transported to the kidneys where it is excreted. Treatment for alkalosis includes Aminoleban ${ }^{\circledR}$ (amino acid agent for liver failure). Constituent electrolytes include sodium $14 \mathrm{mEq} / \mathrm{l}$ and chloride $94 \mathrm{mEq} / \mathrm{l}$. The $14 \mathrm{mEq}$ of chloride is complexed as sodium chloride with the remaining $80 \mathrm{mEq} / \mathrm{l}$ supplied by hydrochloric acid. Aminoleban ${ }^{\circledR}$ contains $80 \mathrm{mEq} / \mathrm{l}$ of $\mathrm{H}^{+}$and is therefore acidic. As such, Aminoleban ${ }^{\circledR}$ is an appropriate agent for the treatment of alkalosis.

Our treatment protocol is outlined as follows: (1) In the presence of mucinous ascites at exploratory laparotomy, we start infusion of the amino acid agent Aminoleban ${ }^{\circledR}$ at $100 \mathrm{ml} / \mathrm{h}$ intravenously until the end of the operation. (2) We irrigate the peritoneal cavity with $250 \mathrm{ml}$ of $7 \%$ sodium bicarbonate for a few minutes and repeat this process eight times for a total volume of $2000 \mathrm{ml}$. (3) BGA is measured frequently (before irrigation, 5, 10, 15, 30, 45, 60, $90 \mathrm{~min}$, upon return to the ward, and on the first day after the operation).

In case 2, we irrigated according to the above protocol with $7 \%$ sodium bicarbonate, and a mild elevation of $\mathrm{pH}$ and $\mathrm{HCO}_{3}{ }^{-}$was recognized after 5 min. $\mathrm{pH}$ and $\mathrm{HCO}_{3}{ }^{-}$ normalized at $90 \mathrm{~min}$ after irrigation. Electrolyte imbalances of hypocalcemia and hypokalemia did not occur. The patient maintained normal vital signs throughout the perioperative period. In this fashion we suggest that severe alkalosis during irrigation with $7 \%$ sodium bicarbonate can be prevented using our treatment protocol, though normalized time from alkalosis is of no consequence.

In conclusion, irrigation with $7 \%$ sodium bicarbonate in the peritoneal cavity is a useful treatment modality to remove mucinous implants of PMP. Administration of amino acid agents before irrigation is an effective countermeasure against critical alkalosis due to systemic absorption of $7 \%$ sodium bicarbonate. Careful monitoring of the acid-base balance and serum electrolytes is critical during irrigation. 
Acknowledgments This work was supported by the Ministry of Education, Culture, Sports, Science and Technology, Japan [Grant Number (22659302), (22591869), (23390392)].

Conflict of interest The authors have no conflict of interest.

\section{References}

1. Ronnett BM, Zahn CM, Kurman RJ et al (1995) Disseminated peritoneal adenomucinosis and peritoneal mucinous carcinomatosis. A clinicopathologic analysis of 109 cases with emphasis on distinguishing pathologic features, site of origin, prognosis, and relationship to "pseudomyxoma peritonei". Am J Surg Pathol 19:1390-1408

2. Ronnett BM, Yan H, Kurman RJ et al (2001) Patients with pseudomyxoma peritonei associated with disseminated peritoneal adenomucinosis have a significantly more favorable prognosis than patients with peritoneal mucinous carcinomatosis. Cancer 92:85-91

3. Watanabe H, Tanahasi S, Kawase H et al (1991) A case of pseudomyxoma peritonei in which sodium bicarbonate was effective in removing mucus. Rinsho Seijinbyo 21:319-323

4. Matsubara M, Tathibana R, Hondo T et al (2005) Three cases of pseudomyxoma peritonei in which sodium bicarbonate was effective in removing mucus. Nihon Sankafujinkagakkai Kanto Rengo Kaiho 42:427-432

5. Shirasawa Y, Orita H, Morimoto Y et al (2008) Critical alkalosis following intraperitoneal irrigation with sodium bicarbonate in a patient with pseudomyxoma peritonei. J Anesth 22:278-281

6. Piver MS, Lele Sb, Patsner B (1984) Pseudomyxoma peritonei: possible prevention of mucinous ascites by peritoneal lavage. Obstet Gynecol 64:95S-96S

7. Shyr YM, Su CH, Wang HC et al (1995) Pseudomyxoma peritonei. Does a true mucolytic agent exist? In vitro and in vivo studies. Am Surg 61:265-270

8. Roy WJ Jr, Thomas BL, Horowitz IR (1997) Acute hyperglycemia following intraperitoneal irrigation with $10 \%$ dextrose in a patient with pseudomyxoma peritonei. Gynecol Oncol 65:360362

9. Bevan KE, Mohamed F, Moran BJ (2010) Pseudomyxoma peritonei. World J Gastrointest Oncol 15:44-50

10. Zhu KJ, Morris DL (2009) Primary peritonectomy/HIPEC for disseminated peritoneal adenomucinosis achieves much lower recurrence rates and better survival than secondary procedures. Surgeon 7:345-350

11. Vaira M, Cioppa T, DE Marco G et al (2009) Management of pseudomyxoma peritonei by cytoreduction + HIPEC (hyperthermic intraperitoneal chemotherapy): results analysis of a twelve-year experience. In Vivo 23:639-644 